\title{
Deep structure of the Ou mountain range strain concentration zone and the focal area of the 2008 Iwate-Miyagi Nairiku earthquake, NE Japan-seismogenesis related with magma and crustal fluid
}

\author{
Tomomi Okada, Norihito Umino, and Akira Hasegawa \\ Research Center for Prediction of Earthquakes and Volcanic Eruptions, Graduate School of Science, \\ Tohoku University, Sendai 980-8578, Japan
}

(Received April 2, 2009; Revised September 25, 2009; Accepted November 11, 2009; Online published March 4, 2010)

\begin{abstract}
The 2008 Iwate-Miyagi Nairiku earthquake (M 7.2) occurred on June 14, 2008 in a zone of concentrated deformation along the mountain backbone of Tohoku encompassing SW Iwate and NW Miyagi Prefectures, NE Japan. This earthquake was a shallow intraplate earthquake with the reverse-type focal mechanism. Regular seismic activity is high in this concentrated deformation zone. We have performed regional-scale seismic tomography in and around the focal area and found that the distinct low-velocity regions are continuously distributed from the mantle wedge to the lower crust just below the focal area and active seismic zones. This low-velocity zone can be interpreted to be a region of partial melting, suggesting that crustal fluids separating and upwelling from deeper portion may be closely related with the occurrence of both the active seismic zones and the 2008 earthquake.
\end{abstract}

Key words: 2008 Iwate-Miyagi Nairiku earthquake, intraplate, focal area, crustal fluids, upwelling, low-velocity belt.

\section{Introduction}

In the Tohoku region (northeast (NE) Honshu), NE Japan, the Pacific Plate subducts beneath the overiding plate. Since the boundary between the Pacific Plate and the overriding plate is coupled in the shallow region, the continental crust (island arc crust) is deformed under compressive stress in the direction of relative motion of the plate, which is approximately east-west. Deformation of the island arc crust due to this compressive stress can be observed from global positioning system (GPS) data. Figure 1 shows the east-west strain distribution obtained from GPS data acquired by the Geographic Survey Institute and Tohoku University between 1997 and 2001 (Miura et al., 2004). Blue indicates regions of compressive strain and red shows regions of tensile strain. A prominent region of compressive strain can be identified along the Ou Mountain Range (Miura et al., 2002). The existence of this a region can also be confirmed from the distribution of horizontal crustal deformation velocity over the last 100 years (Hasegawa et al., 2000). Several earthquakes have occurred in this zone of concentrated deformation along the Ou Mountain Range, including a number of large ones (for example, the 1896 Rikuu earthquake), as shown in Fig. 1(a).

Hasegawa et al. (2005) hypothesized on the possible source of such a concentrated deformation of the crust in

Copyright (C) The Society of Geomagnetism and Earth, Planetary and Space Sciences (SGEPSS); The Seismological Society of Japan; The Volcanological Society of Japan; The Geodetic Society of Japan; The Japanese Society for Planetary Sciences; TERRAPUB.

doi: $10.5047 /$ eps.2009.11.005
NE Japan. The distribution of $S$-wave velocity perturbation at a depth of $40 \mathrm{~km}$ in this region is shown in Fig. 2(a) (Nakajima et al., 2001). In a subduction zone such as Tohoku, the hydrated minerals in the subducting oceanic slab (Pacific Plate) undergo dehydration and decomposition as the temperature and pressure of the slab increase with subduction, and the water thus released migrates into the overlying mantle wedge. This water is eventually entrained in an upwelling sheet flow within the mantle wedge, penetrating into the crust just beneath the volcanic front (i.e., the Ou Mountain Range). Figure 2(a) depicts a distinct lowvelocity belt that corresponds to the upwelling flow that reaches the Moho along the mountain range. As the seismic velocity is lower in regions of high temperature and large amounts of fluid, the upwelling flow, as well as the magma and crustal fluid, can be imaged as regions of lower $S$-wave velocity (Fig. 2(b)). When the melt within the upwelling flow intrudes into the crust and cools, water released from the solidified melt migrates upward. Through this process, water from the subducted Pacific slab is transported to the shallow crust beneath the mountain range.

In the backbone mountain range, where melt and water are present in the lower crust, it is expected that the crust will be relatively weak in comparison with the surrounding areas. Therefore, under compression in the direction of relative plate motion, the crust in the backbone range undergoes partially anelastic deformation, which can lead to local contraction and uplift and, consequently, the formation of the belt of concentrated deformation (Hasegawa et al., 2005). 


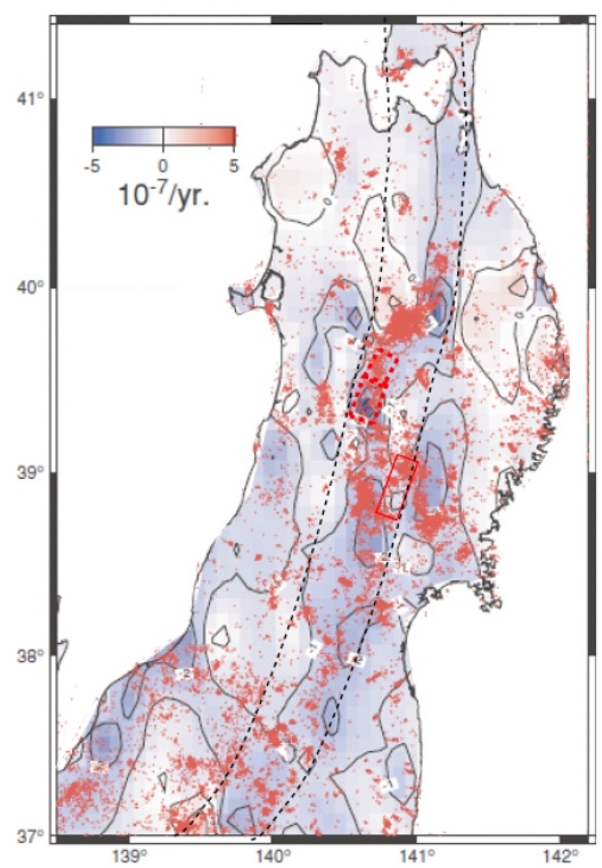

Fig. 1. East-west component of strain rate by GPS observation (Miura et al., 2004) based on data from 1997 to 2001. Red dots denote the epicenters of micro-earthquakes (1997-2001, all magnitudes, depth $<40 \mathrm{~km}$ ). The focal areas of the 2008 Iwate-Miyagi earthquake and the 1896 Rikuu earthquake (M 7.2) (Umino et al., 2000) are indicated by the open and broken red rectangles, respectively. The area between the broken lines corresponds to the area of the Ou-Mountain Range.
The source region of the 2008 Iwate-Miyagi Nairiku earthquake is indicated by the solid red rectangle in Figs. 1 and 2. This earthquake was an intraplate earthquake that occurred in the concentrated deformation zone along the $\mathrm{Ou}$ Mountain Range. In the study reported here, we examined the hypocentral region in more detail with the aim of determining the relationship between the concentrated deformation zone, including the hypocentral region, of the 2008 Iwate-Miyagi Nairiku earthquake and the upwelling fluid that can be imaged as a seismic low-velocity zone.

A number of seismic tomographic studies have already been performed in this area. Nakajima and Hasegawa (2003) found two branches of a seismic low-velocity zone in the crust that seem to reach the Naruko volcano and the area of a moderate-sized earthquake (the 1962 northern Miyagi Prefecture earthquake). Detailed seismic velocity structure data are necessary to investigate just where such branches of the seismic low-velocity zone are widely distributed and how they are spatially related with the shallow seismicity that includes the 2008 earthquake. Wang et al. (2008) found a seismic low-velocity zone beneath the focal area of the 2008 earthquake using data from routinely operated stations. However, to date, a spatial correlation (observed by Nakajima and Hasegawa, 2003) between such a low-velocity zone in the lower crust and shallow crustal seismicity have not been clearly shown in the surrounding area, including the Ou backbone range strain concentration zone. In our study, we used more dense data from not only routinely operated stations but also from a number of dense temporary stations operated by Tohoku University and other institutions in order to obtain a more detailed picture of the

(a)

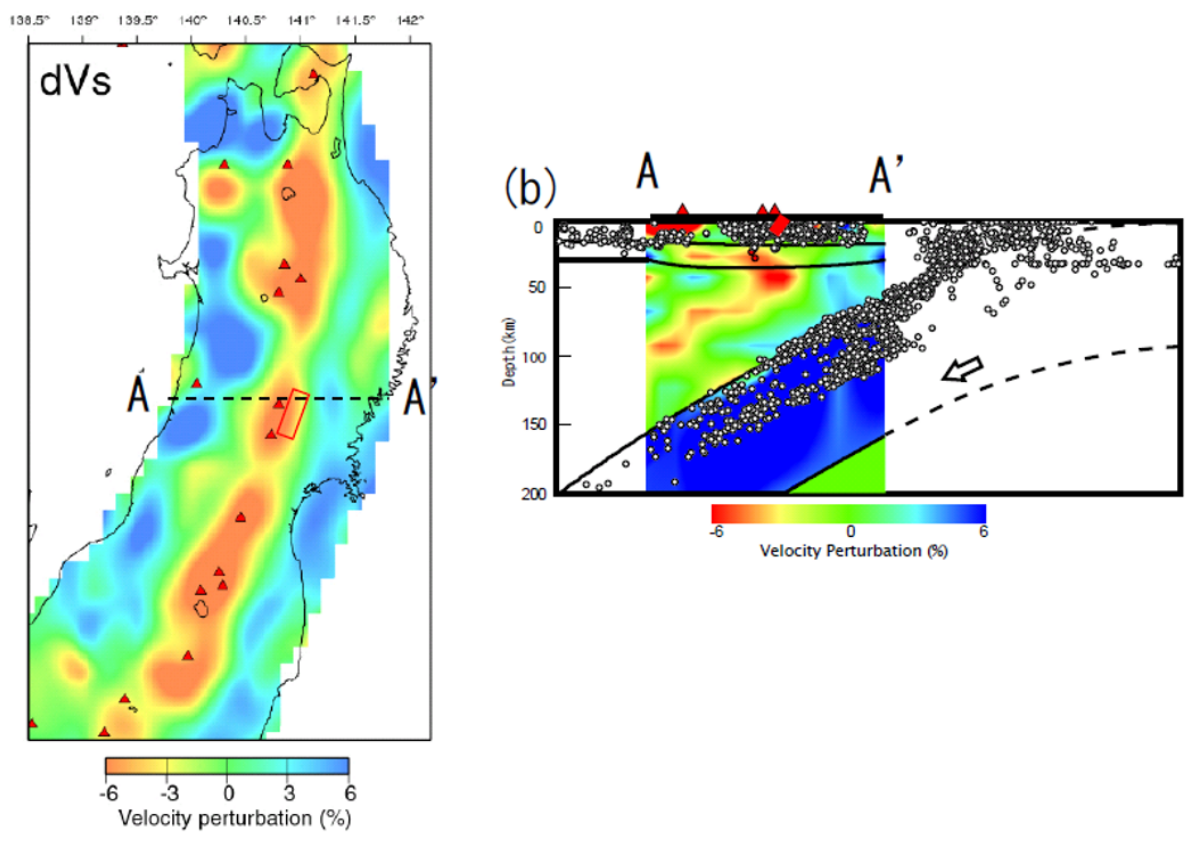

Fig. 2. (a) $V_{s}$ perturbation at a depth $40 \mathrm{~km}$ (Nakajima et al., 2001). Triangles denote volcanoes. The focal area of the 2008 Iwate-Miyagi earthquake is indicated by the open red rectangule. (b) Vertical cross section of $V_{s}$ perturbation along A-A'. White circles denote hypocenters (1997-1999, all magnitudes, within 0.125 degrees from the cross section). Thick lines denote the Conrad, Moho discontinuities and upper surface of the subducting Pacific Plate, respectively. The bold red line denotes the possible fault plane of the 2008 Iwate-Miyagi earthquake. 
seismic velocity structure, particularly in the lower crust, in a wider area.

\section{Data and Method}

We performed regional-scale tomography using dense temporary seismic networks in and around the focal area of the 2008 Iwate-Miyagi Nairiku earthquake, determining the three-dimensional seismic velocity structure and relocating hypocenters simultaneously using double-difference tomography (Zhang and Thurber, 2003). Figure 3 shows the data set used in this study. Travel time data were obtained from the Japanese universities joint seismic observation in the Tohoku Backbone range (1997-1998) and the aftershock observation for the 2003 Northern Miyagi earthquake (Okada et al., 2003; Umino et al., 2003). We also used data from routinely operated stations of Tohoku University, JMA, and Hi-net in the period from 1997 to 2007. Note that we have included the events (blue) within the subducting Pacific slab in the tomography inversion in order to image the lower crust structure. The initial velocity structure is taken from Hasegawa et al. (1978). The total number of earthquakes is 25844 . We used a grid net with an interval of about $6 \mathrm{~km}$ ( 0.5 degrees). The depth of the interval was also $6 \mathrm{~km}$. The numbers of $P$ - and $S$-wave arrival times are 504362 and 381719, respectively, and those of DD for $P$ and $S$-wave arrival times are 2668428 and 1885441 , respectively. The travel time residual varies from 0.24 to $0.09 \mathrm{~s}$.

Figures 4 and 5 show the checkerboard resolution test. The perturbation for the checkerboard pattern is $5 \%$. The checkerboard consists of four east-west vertical across-fault cross sections ordered from north to south. Figure 4 shows that the pattern on a scale of about $10 \mathrm{~km}$ could be reproduced well in the upper crust and some parts of the lower crust. Figure 5 shows the pattern on a scale of about $20 \mathrm{~km}$ could be reproduced well in the whole crust. The resolution is estimated to be about $10 \mathrm{~km}$ in the upper crust and $10-20 \mathrm{~km} \times 20 \mathrm{~km}$ in lower crust.

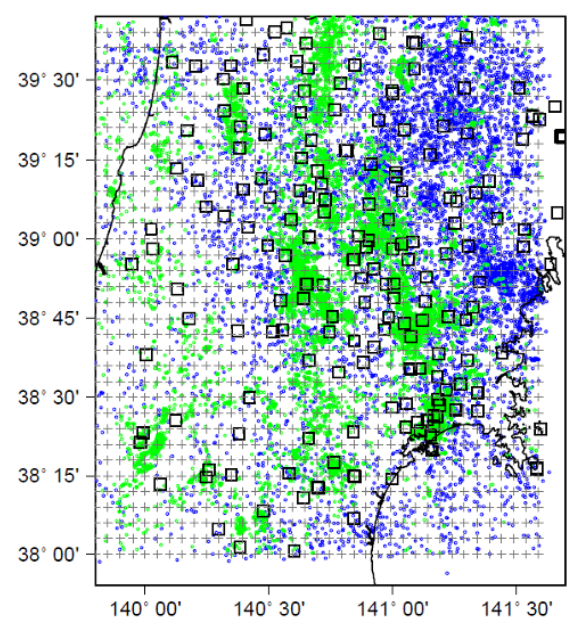

Fig. 3. Data set used for the seismic tomography study. Squares denote the seismic stations used in this study. Green and blue small dots denote the shallow seismicity and the seismicity, respectively, within the subducting Pacific Plate slab. Gray crosses denote the grids used in the tomography. We set the grids at depths of $0,6,12,18,24,40,60$, $80,100,120,140$, and $160 \mathrm{~km}$.
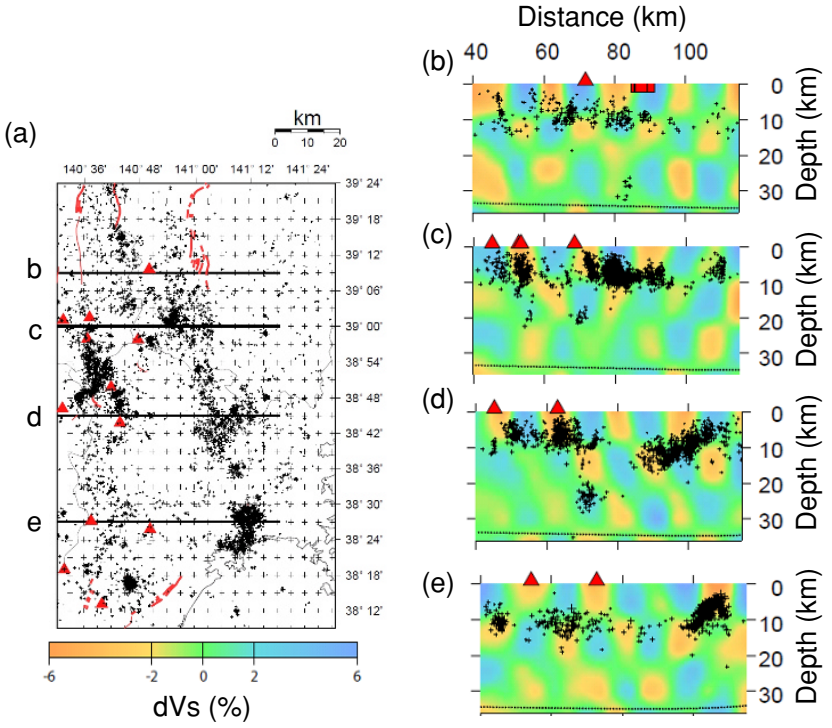

Fig. 4. Result of the checkerboard resolution test. We used the synthetic checkerboard pattern with a scale of about $10 \mathrm{~km}$. Four east-west vertical cross sections are shown in (b) to (e). The location of each cross section is shown in (a). Small crosses denote the hypocenters within 0.05 degrees from each cross section. Triangles and bold red lines (boxes) denote Quaternary volcanoes and active faults (The Research Group for Active Faults of Japan, 1991), respectively. The thin broken line denotes the Moho discontinuity (Zhao et al., 1990).
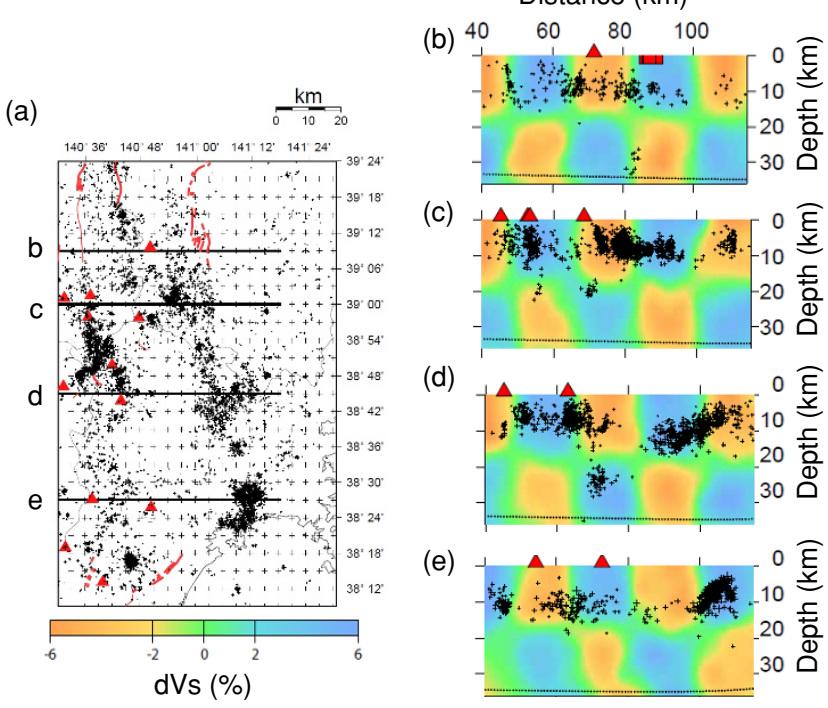

(c)

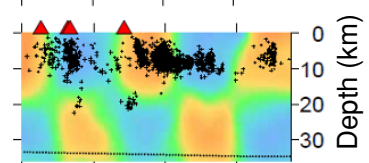

(d)

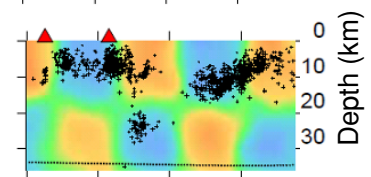

(e)

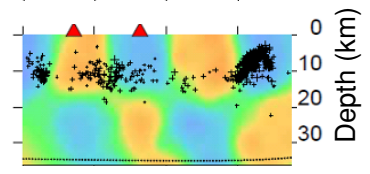

Fig. 5. Result of the checkerboard resolution test. We used the synthetic checkerboard pattern on a scale of about $10 \mathrm{~km}$. Others are the same as Fig. 4.

\section{Results and Discussion}

\subsection{Relation between shallow seismic activity and deep} crustal structure

The relationship between seismic activity and the deep structure in and around the focal region of the 2008 earthquake is shown in Fig. 6. The epicenters of shallow earthquakes and the possible faults of earthquakes $\geq M 5.5$ are shown in the left pane (Fig. 6(a)), and $S$-wave velocity perturbations at a depth of $24 \mathrm{~km}$ are shown in the right pane (Fig. 6(b)). In this region, you can see two parallel seismic 
(a)

Shallow seismicity

(b) $\mathrm{dVs}(\%) 24 \mathrm{~km}$ depth

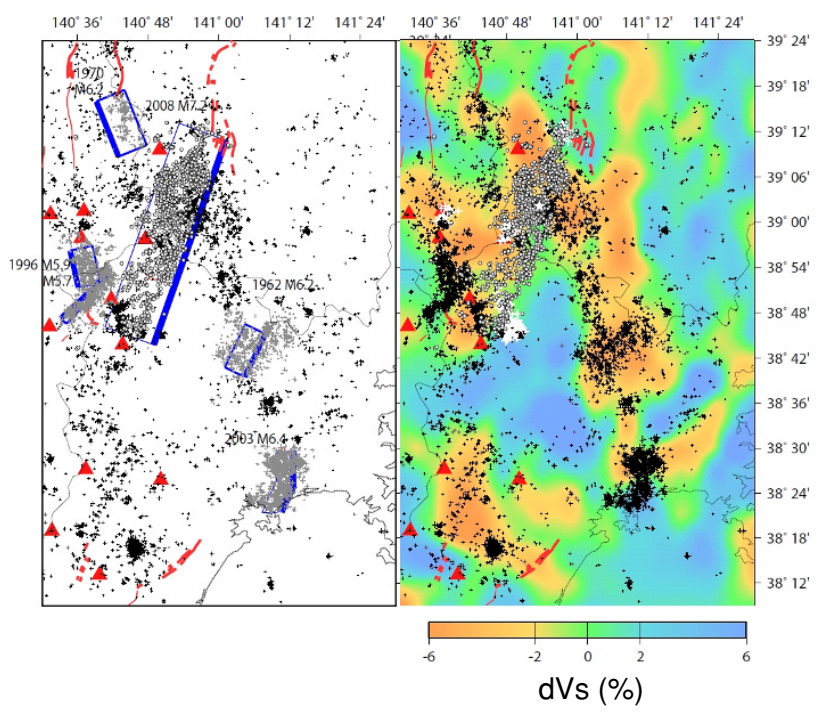

Fig. 6. Comparison of the spatial distribution of shallow seismicity and lower crustal structure. (a) Epicenter of shallow seismicity (depth $<45 \mathrm{~km}$ ) is denoted by a small cross. The blue rectangle shows the horizontal projection of the plausible fault of the earthquake with a magnitude $>5.5$ (bold line denotes the shallower edge of the fault). The aftershocks of these earthquakes are shown by small gray crosses (Umino et al., 2000). Red triangles and bold red lines (boxes) denote quaternary volcanoes and active faults, respectively. White star and small circles denote the mainshock and the aftershocks of the 2008 earthquake, respectively. (b) $V_{s}$ perturbation at a depth of $24 \mathrm{~km}$. The white cross denotes the low-frequency micro-earthquakes.

belts elongated in north-south direction: one is an active seismic zone that extends north-south along the Ou Mountain Range (left edge of figure), and the other is a seismically active zone oriented approximately parallel to the first zone with a SSE-NNW alignment (center and right of figure). These two seismic zones correspond to the two regions of east-west compressive strain in Fig. 1. We relocated the main shock hypocenter of the 2008 earthquake and the 1276 aftershocks that occurred within 1 week after the main shock using the seismic velocity structure modeled in this study. The 2008 earthquake occurred in the region where these two subparallel seismic zones appear to converge.

Low-velocity regions extending north-south can be seen just below the two seismic zones (shown by brackets marked with $\mathrm{W}$ and $\mathrm{E}$ in Fig. 7) in the lower crust shown in Figs. 6 and 8. This low-velocity zone is also for $P$-waves and it has a high $V_{p} / V_{s}$ (Fig. 7), suggesting the possible interpretation that this low-velocity zone is the zone with melt and/or high pressurized fluid (e.g., Takei, 2002). In this case, one of the possible interpretations of these lowvelocity regions, which are continuously distributed from the uppermost mantle, is that they are the regions of partial melting that originate from the upwelling flow within the mantle wedge. As such this upwelling flow may be the source of large amounts of fluid supplied from depth (compare Introduction; Nakajima et al., 2001; Hasegawa et al., 2005). Low-frequency micro-earthquakes, which would be related by fluid movement, occur at depths $>20 \mathrm{~km}$ (see Fig. 6) near the edge of the low-velocity zone. (a)

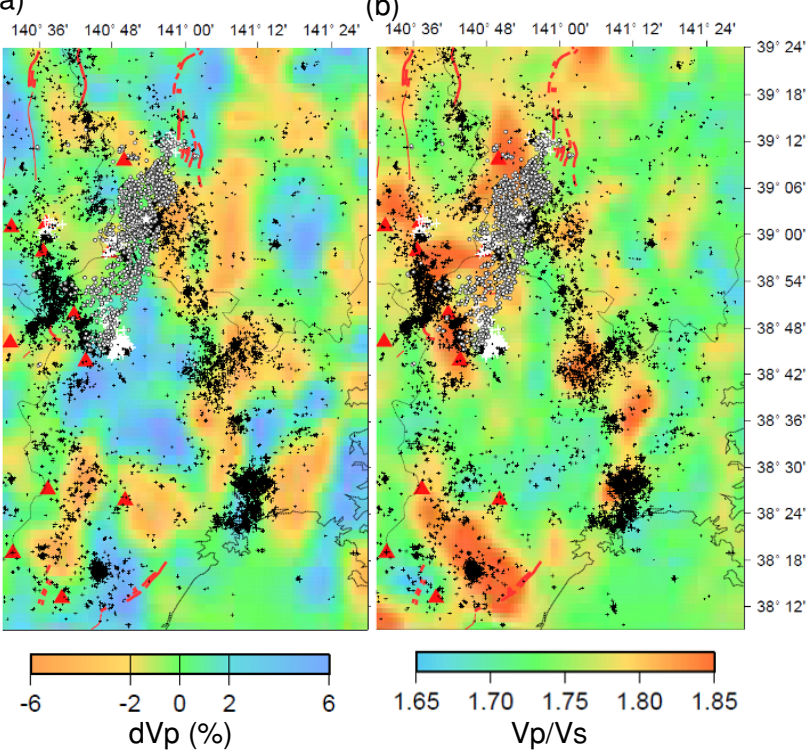

Fig. 7. (a) $V_{p}$ perturbation at a depth of $24 \mathrm{~km}$. (b) $V_{p} / V_{s}$ distribution at a depth of $24 \mathrm{~km}$. Other $V_{p} / V_{s}$ distributions are the same as in Fig. 6(b).

(a)

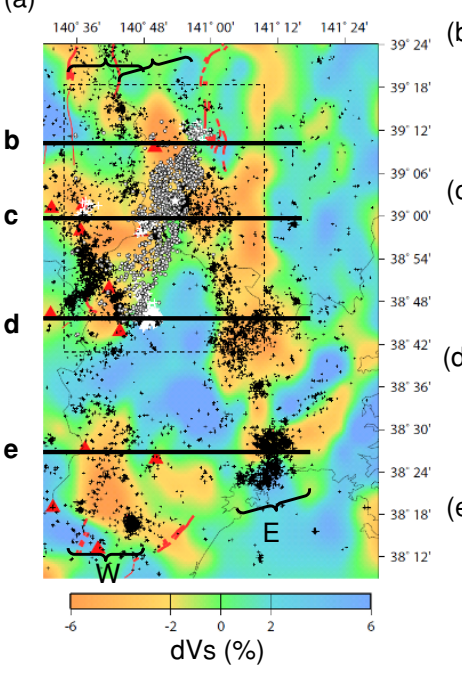

Distance $(\mathrm{km})$

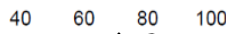

(b)

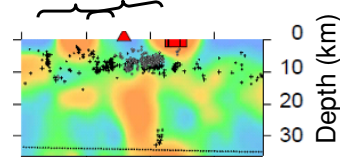

(c)

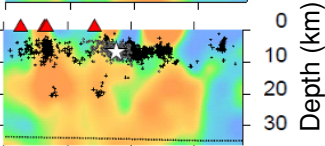

d)

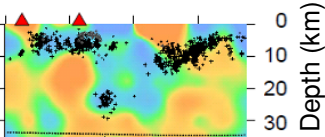

(e)

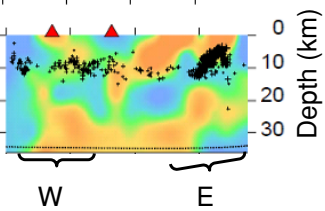

Fig. 8. (a) $V_{s}$ perturbation at a depth of $24 \mathrm{~km}$. Small crosses denote the hypocenters. White star and small circles denote the mainshock and the aftershocks of the 2008 earthquake, respectively. Triangles and bold red lines denote Quaternary volcanoes and active faults, respectively. Brackets marked with $\mathrm{W}$ and $\mathrm{E}$ show the locations of low-velocity zones (and seismic belt in upper crust) beneath the volcanic front and the forearc region, respectively. (b), (c), (d), and (e) East-west vertical cross sections are shown. The location of each cross section is shown on the left of (a). Small crosses denote the hypocenters within 0.05 degrees from each cross section. Triangles and red boxes denote Quaternary volcanoes and active faults, respectively. The thin broken line denotes the Moho discontinuity (Zhao et al., 1990).

Low-velocity regions have been recognized just below the source regions of the 1962 North Miyagi earthquake (M 6.2), the 1996 Akita-Miyagi earthquake (M 5.9) (Nakajima and Hasegawa, 2003; Asano et al., 2004) (Fig. 7(d)), the 1970 South Akita earthquake (M 6.2) (Umino et al., 2000) (Fig. 7(b)), and the 2003 North Miyagi 
earthquake (M 6.4) (Okada et al., 2003; Umino et al., 2003) (Fig. 7(e)). It thus appears that fluid supplied from a deeper portion contributed to the occurrence of these earthquakes (e.g., Miller et al., 2004).

For example, in the cases of the 2003 North Miyagi earthquake, the source fault was found to have steep dips. It has therefore been inferred that the source was reactivated through the compressive inversion of normal faults formed during the opening of the Japan Sea (Okada et al., 2003; Umino et al., 2003). For this kind of inversion of a steeply dipping normal fault (as a reverse fault) to occur, there would have to be high pore-fluid pressure to reduce the frictional strength acting on the fault (Sibson, 1990). The lowvelocity region in the source region has been identified as a fluid source, and it has been inferred that the source region itself has high pore-fluid pressure (Okada et al., 2007).

The focal area of the 2008 earthquake is located where these two seismic zones and the seismic low-velocity zone in the lower crust are closely located. The presence of a low-velocity region just beneath the source region of the main shock of the 2008 earthquake (see Fig. 7(c)) similarly suggests that fluid supplied from depth contributed to the occurrence of this earthquake.

However, the resolution in our study may not be fine enough to discuss the shallow structure that shows the path of fluid in the mid- to upper crust separated from the possible partial melt in the lower crust, which is imaged as a low-velocity zone in this study. A more detailed description of the seismic velocity structure in and around the fault of the 2008 earthquake based on dense aftershock observation data (e.g., Okada et al., 2009) is necessary for further discussion of this subject.

\subsection{Upwelling magma flow to the volcanoes and its re- lation with the fault of the $\mathbf{2 0 0 8}$ earthquake}

The hypocentral region of the 2008 earthquake is near the Mts. Yakeishi-dake, Kurikoma, Onikobe, and Naruko volcanoes. The path taken by the upwelling magma to reach these active volcanoes would be closely located to the source fault of the 2008 earthquake. To examine this point in more detail, we compared the aftershock distribution with the seismic velocity structure determined in our study. The obtained distributions of $S$-wave velocity deviation at depths of $6,12,18,24$ and $40 \mathrm{~km}$ are shown in Fig. 9; the main shocks and aftershocks as well as an outline of the aftershock region are also shown in this figure. As seen in Fig. 1(b), the upwelling flow that extends to the Moho directly below the backbone mountains is distinctly imaged as a low-velocity region that extends N-S at a depth of $40 \mathrm{~km}$. Melt in the upwelling region is expected to intrude into the crust, which should be observable as a low-velocity region at a depth of approximately $24 \mathrm{~km}$. At this depth, a branching of the low-velocity region can be seen, with one branch extending directly to the volcanic front, and the other extending to the eastern forearc region. The deep low-frequency micro-earthquakes (denoted by white crosses), which would be related with the migration of fluid (Hasegawa and Yamamoto, 1994), are located near the margin of these low-velocity regions. The low-velocity region just below the volcanic front extends further at a shallower depth, and the branches reach below

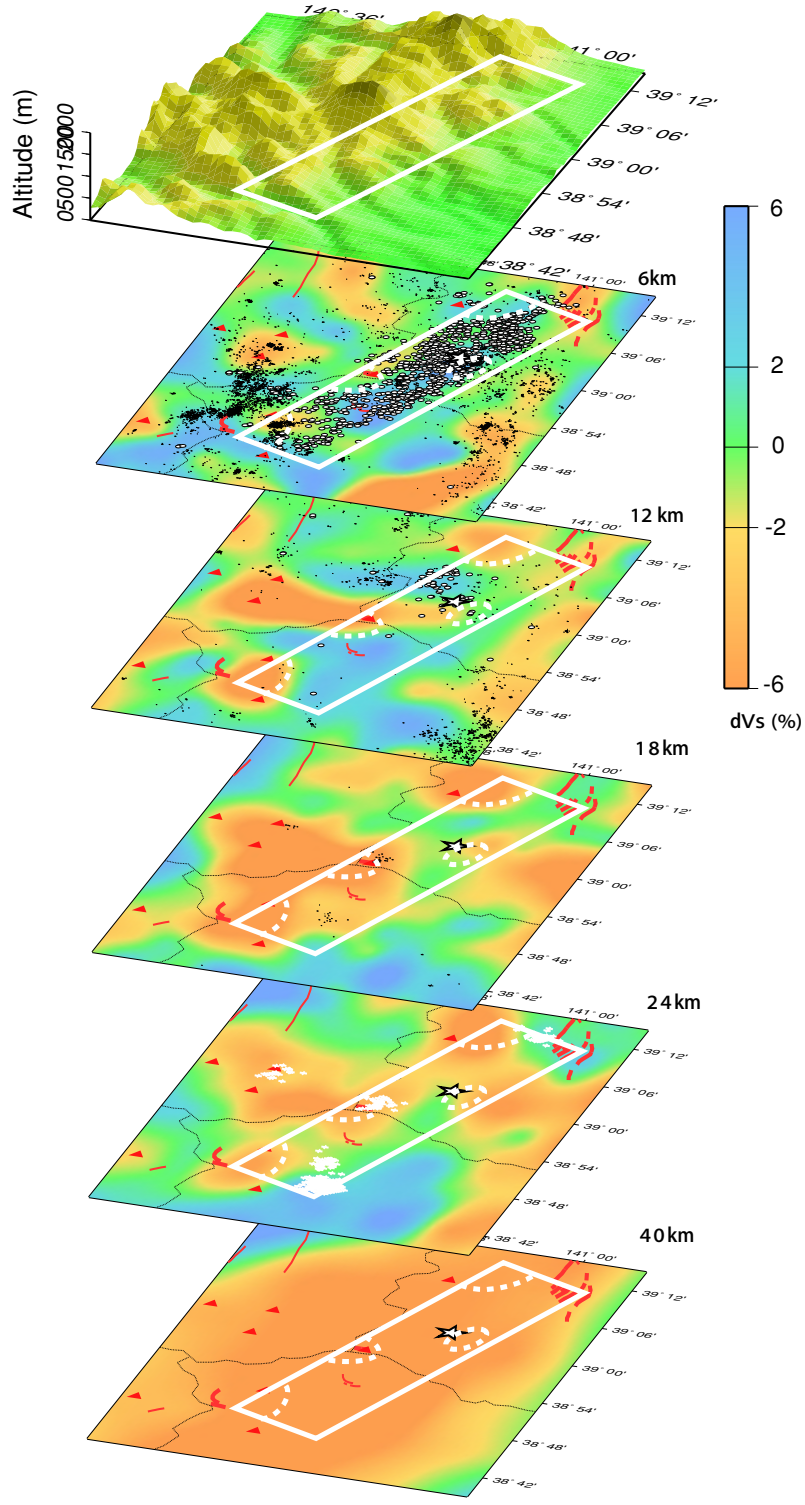

Fig. 9. Horizontal slices of $V_{s}$ perturbation at depths of $6,12,18,24$, and $40 \mathrm{~km}$. Star denotes the epicenter of the 2008 main shock. White circles and small crosses denote the aftershocks and other microearthquakes (1997-2007). White rectangular denotes the horizontal projection of the aftershock area, and the areas with less aftershocks are shown by broken lines. White small crosses at a depth of $24 \mathrm{~km}$ denote low-frequency earthquakes.

Mts. Yakeishi-dake and Kurikoma and the Naruko volcanoes from north to south $(6-18 \mathrm{~km})$. The focal area of the 2008 event as estimated from the aftershock distribution at depths of 6 and $12 \mathrm{~km}$ is located just above and between these shallow branches of magma flow, which are imaged as low-velocity regions. Note that there are some areas with low aftershock activities, which are encircled by the broken lines in Fig. 8. These areas show that low-velocity regions have a higher temperature, which make the crustal rocks aseismic because the strength of the crust strongly depends on thermal condition. (see Scholz, 1990 for review). The spatial relation between a large intraplate earthquake and an active volcano, and the relation between the width of the brittle seismogenic layer and earthquake occurrence have been discussed in previous studies. Ito (1999) hypoth- 
esized on the occurrence of inland (intraplate) earthquakes in which a large earthquake tended to occur in an area with a large lateral variation in the thickness of the seismogenic crust, where large amounts of stress concentrated. Kudo et al. (2009) found a relation between the upper limit of inland (intraplate) earthquake magnitude and the geothermal gradient: larger earthquakes occurred where smaller a geothermal gradient was observed. Such spatial variations in the thickness of the crust may also have affected the occurrence of the 2008 earthquake.

\section{Conclusions}

The 2008 Iwate-Miyagi earthquake occurred in an area of concentrated deformation along the Ou backbone mountain range of Tohoku, in the vicinity of several active volcanoes, including Mts. Kurikoma and Yakeishi-dake and the Onikobe and Naruko volcanoes. We have found a distinct seismic low-velocity zone just beneath the concentrated deformation zone and the focal area of the 2008 Iwate-Miyagi earthquake by seismic tomography using regional seismic observation data. The low-velocity zone extends from the uppermost mantle to each active volcano at the surface. These observations suggest that the high-temperature upwelling partial melt and the crustal fluid released from it are closely related with the concentration of crustal deformation and the occurrence of the 2008 Iwate-Miyagi earthquake.

Acknowledgments. We used data from JMA and Hi-net/NIED as well as from JNES (Japan Nuclear Energy Safety Organization). We thank Prof. Cliff Thurber and Dr. Haijang Zhang for providing their programs and valuable discussion. We also thank R. Sibson, S. Miura, J. Nakajima, N. Uchida, Y. Ohta, T. Iinuma, M. Ohzono and T. Matsuzawa for fruitful discussion. We acknowledge T. Sato, S. Hori, K. Tachibana, T. Kono, T. Nakayama, S. Hirahara and S. Suzuki for their efforts during the seismic observations. We would like to thank the editor (Takashi Iidaka), and the reviewers (Shinji Toda and an anonymous reviewer) for helpful comments. This work was conducted with the support of Grant-in-Aid for Special Purposes, MEXT, Japan.

\section{References}

Asano, Y., K. Obara, J. Nakajima, and A. Hasegawa, Inhomogeneous crustal structure beneath northern Miyagi prefecture, northeastern Japan, imaged by coda envelope inversion: Implication for fluid distribution, Geophys. Res. Lett., 31, 2004GL021261. 2004.

Hasegawa, A. and A. Yamamoto, Deep, low-frequency microearthquakes in or around seismic low-velocity zones beneath active volcanoes in northeastern Japan, Tectonophysics, 223, 233-252, 1994.

Hasegawa, A., N. Umino, and A. Takagi, Double-planed structure of the deep seismic zone in the northeastern Japan arc, Tectonophysics, 47, 43-58, 1978

Hasegawa, A., A. Yamamoto, N. Umino, S. Miura, S. Horiuchi, D. Zhao, and H. Sato, Seismic activity and deformation process of the crust within the overriding plate in the northeastern Japan subduction zone, Tectonophysics, 319, 225-239, 2000.

Hasegawa, A., J. Nakajima, N. Umino, and S. Miura, Deep structure of the northeastern Japan arc and its implications for crustal deformation and shallow seismic activity, Tectonophysics, 403, 59-75, 2005.

Ito, K., Seismogenic layer, reflective lower crust, surface heat flow and large inland earthquakes, Tectonophysics, 306, 423-433, 1999.
Kudo, T., Y. Tanaka, and M. Furumoto, Estimation of the maximum earthquake magunitude from the geothermal gradient, Bull. Seismol. Soc. Am., 99, 396-399, 2009.

Miller, S. A., C. Colletini, L. Chairaluce, M. Cocco, M. Marchi, and B. J. Kaus, Aftershocks driven by a high-pressure $\mathrm{CO} 2$ source at depth, Nature, 427, 724-727, 2004.

Miura, S., T. Sato, K. Tachibana, Y. Satake, and A. Hasegawa, Strain accumulation in and around Ou Backbone Range, northeastern Japan as observed by a dense GPS network, Earth Planets Space, 54, 10711076, 2002.

Miura, S., T. Sato, A. Hasegawa, Y. Suwa, K. Tachibana, and S. Yui, Strain concentration zone along the volcanic front derived by GPS observations in NE Japan arc, Earth Planets Space, 56, 1347-1355, 2004.

Nakajima, J. and A. Hasegawa, Tomographic imaging of seismic velocity structure in and around the Onikobe volcanic area, northeastern Japan: implications for fluid distribution, J. Volcanol. Geotherm. Res., 127, 1$18,2003$.

Nakajima, J., T. Matsuzawa, A. Hasegawa, and D. Zhao, Threedimensional structure of $\mathrm{Vp}$, Vs and $\mathrm{Vp} / \mathrm{Vs}$ beneath the northeastern Japan arc: Implications for arc magmatism, J. Geophys. Res, 106, 21843-21857, 2001.

Okada, T., N. Umino, and A. Hasegawa, Rupture process of July 26 2003 northern Miyagi earthquake sequence, NE Japan, estimated from double-difference hypocenter locations, Earth Planets Space, 55, 741$750,2003$.

Okada, T., A. Hasegawa, J. Suganomata, N. Umino, H. Zhang, and C. Thurber, Imaging the heterogeneous source area of the 2003 M6.4 northern Miyagi earthquake, NE Japan, by double-difference tomography, Tectonophysics, 430, 57-81, 2007.

Okada, T., N. Umino, A. Hasegawa, and Group for the aftershock observation of the 2008 Iwate-Miyagi Nairiku Earthquake, Hypocenter distribution and heterogeneous seismic velocity structure in and around the focal area of the 2008 Iwate-Miyagi Nairiku earthquake, NE JapanSeismological evidence for a possible fluid driven compressional inversion earthquake, Earth Planets Space, 2009 (submitted).

Scholz, C., The Mechanics of Earthquakes and Faulting, 461 pp., Cambridge University Press, New York, 1990.

Sibson, R. H., Rupture nucleation on unfavorably oriented faults, Bull. Seismol. Soc. Am., 80, 1580-1604, 1990.

The Research Group for Active Faults of Japan, Active Faults in Japan: Sheet maps and inventories (revised edition), 437 pp., University of Tokyo Press, Tokyo, 1991.

Takei, Y., Effect of pore geometry on Vp/Vs: From equilibrium geometry to crack, J. Geophys. Res., 107, doi:10.1029/2001JB000522, 2002.

Umino, N., K. Nida, A. Hasegawa, and H. Sato, Microearthquake activity in the focal areas of large earthquakes that occurred in the last $\sim 100$ years in northeastern Japan, available at http://wwwsoc. nii.ac.jp/jepsjmo/cd-rom/2000cd-rom/pdf/se/se-018_e.pdf, Abstract for the 2000 Joint Meeting for Earth and Planetary Science, Japan, Se-018, 2000.

Umino, N., T. Okada, J. Nakajima, S. Hori, T. Kono, T. Nakayama, N. Uchida, J. Shimizu, J. Suganomata, S. Gamage, A. Hasegawa, and Y. Asano, Hypocenter and focal mechanism distributions of aftershocks of July 262003 M6.4 northern Miyagi, NE Japan, earthquake revealed by temporary seismic observation, Earth Planets Space, 55, 719-730, 2003.

Wang, Z., Y. Fukao, S. Kodaira, and R. Huang, Role of fluids in the initiation of the 2008 Iwate earthquake (M7.2) in northeast Japan, Geophys. Res. Lett., 35, doi:10.1029/2008GL035869, 2008.

Zhang, H. and C. Thurber, Double-Difference Tomography: the method and its application to the Hayward Fault, California, Bull. Seismol. Soc. Am., 93, 1875-1889, 2003.

Zhao, D., S. Horiuchi, and A. Hasegawa, 3-D seismic wave velocity structure of the crust in the northeastern Japan arc, Tectonophysics, 181, 135$149,1990$.

T. Okada (e-mail: okada@aob.geophys.tohoku.ac.jp), N. Umino, and A. Hasegawa 